\title{
Measuring integrated HIV DNA ex vivo and in vitro provides insights about how reservoirs are formed and maintained
}

\author{
Marilia Rita Pinzone and Una O'Doherty ${ }^{*}$
}

\begin{abstract}
The identification of the most appropriate marker to measure reservoir size has been a great challenge for the HIV field. Quantitative viral outgrowth assay (QVOA), the reference standard to quantify the amount of replication-competent virus, has several limitations, as it is laborious, expensive, and unable to robustly reactivate every single integrated provirus. PCR-based assays have been developed as an easier, cheaper and less error-prone alternative to QVOA, but also have limitations. Historically, measuring integrated HIV DNA has provided insights about how reservoirs are formed and maintained. In the 1990s, measuring integrated HIV DNA was instrumental in understanding that a subset of resting CD4 T cells containing integrated HIV DNA were the major source of replication-competent virus. Followup studies have further characterized the phenotype of these cells containing integrated HIV DNA, as well as shown the correlation between the integration levels and clinical parameters, such as duration of infection, CD4 count and viral load. Integrated HIV DNA correlates with total HIV measures and with QVOA. The integration assay has several limitations. First, it largely overestimates the reservoir size, as both defective and replication-competent proviruses are detected. Since defective proviruses are the majority in patients on ART, it follows that the number of proviruses capable of reactivating and releasing new virions is significantly smaller than the number of integrated proviruses. Second, in patients on ART clonal expansion could theoretically lead to the preferential amplification of proviruses close to an Alu sequence though longitudinal studies have not captured this effect. Proviral sequencing combined with integration measures is probably the best estimate of reservoir size, but it is expensive, time-consuming and requires considerable bioinformatics expertise. All these reasons limit its use on a large scale. Herein, we review the utility of measuring HIV integration and suggest combining it with sequencing and total HIV measurements can provide insights that underlie reservoir maintenance.
\end{abstract}

Keywords: ART, HIV, Integrated HIV DNA, Proviral DNA, Reservoir, Sequencing

\section{Background}

The introduction of combination antiretroviral therapy (ART) has profoundly modified the history of human immunodeficiency virus (HIV) infection. The majority of patients on ART have undetectable viral loads and life expectancy close to the general population [1-3]. Unfortunately, ART is not curative, and in the majority of individuals HIV viral load promptly rebounds after ART cessation. This is due to the presence of long-lived viral

*Correspondence: unao@pennmedicine.upenn.edu Department of Pathology and Laboratory Medicine, University of Pennsylvania, Philadelphia, PA, USA reservoirs, containing replication-competent proviruses, which currently represent the barrier to any curative approach [4-6]. "Shock and kill" strategies rely on the activation and immune clearance of viral reservoirs. The evaluation of efficacy of such interventions requires the accurate measure of the individual viral reservoir.

Measuring HIV reservoirs has been challenging. Historically, quantitative viral outgrowth assay (QVOA) has been considered the reference standard to measure the fraction of the HIV reservoir that is replication-competent [7]. Polymerase chain reaction (PCR)-based assays, such as total and integrated HIV DNA, have represented a cheaper, less time-consuming and less error-prone 
approach to study the reservoir, but have their own shortcomings $[8,9]$.

In this review, we summarize the technical and clinical strengths, as well as the weaknesses of measuring integrated HIV DNA. We also discuss the scenarios where, despite its limitations, integrated HIV DNA can still provide useful information, especially when combined with other techniques, such as proviral sequencing.

\section{The challenge of measuring HIV reservoir size}

Measuring integrated HIV DNA has been instrumental in increasing our understanding of HIV biology. In the 1990s, Siliciano's group published the first groundbreaking studies showing that resting CD4 $\mathrm{T}$ cells containing integrated HIV DNA were the main reservoir in patients on ART $[10,11]$. The authors showed that replication-competent virus could be induced in vitro from resting CD4 $\mathrm{T}$ cells of patients with undetectable viremia by using QVOA. Initially, it was thought that latently infected cells form when HIV integrates in activated cells just before they return to a resting state [10-15]. However, additional studies demonstrated that resting CD4 $\mathrm{T}$ cells can be directly infected with HIV with delayed kinetics [16-25].

Historically, QVOA was extremely important because it captured a relevant attribute of the reservoir-that cells persisted without making any virus unless they were stimulated and then could produce virus. This was conceptually important because it explained why the reservoir was resistant to therapy. The assay relies on the purification of large numbers of resting $\mathrm{CD} 4 \mathrm{~T}$ cells usually by negative selection, which are cultured in the presence of target cells to amplify released virions and activators to stimulate infected cells to release virions. QVOA requires a large amount of blood $(\sim 200 \mathrm{ml})$, or a leukapheresis product, in order to obtain the required number of resting CD4 T cells. QVOA is based on the limiting dilution method and the results are typically expressed as infectious units per million cells (IUPM) [7]. QVOA as currently performed is an underestimate of reservoir size as it is difficult to stimulate every replication-competent provirus. In fact, repeated stimulation of initially negative wells leads to reactivation of proviruses that were not induced in the previous round of stimulation [26]. This could be due to the stochastic nature of HIV reactivation [27]. Notably, repeated rounds of T cell stimulation can reactivate many of the latent proviruses that are resistant to expression. Proviral sequencing suggests the reservoir may be 6-fold larger than QVOA estimates [26]. Proviral sequencing studies have further called into question the value of QVOA as more intact proviruses were identified in effector memory (TEM) > transitional memory $(\mathrm{TTM})>$ naive > central memory $(\mathrm{TCM}) \mathrm{T}$ cells [28], while QVOA suggested that TCM contained the largest fraction of replication-competent proviruses [29].

After ART interruption virological rebound always occurs even when the reservoir is extremely small, as shown by the Mississippi baby [30] and the Boston patients [31,32]. "Undetectable" HIV in these publications indicates not detected in a large volume of blood (typically $\sim 180 \mathrm{ml}$ or $\sim 20-50$ million CD4s). These patients could now be described as having reservoirs below a certain detection limit, such as $<1$ infectious unit per 50 million CD4s. QVOA is not appropriate to detect small changes in the size of the reservoir that may occur in pilot clinical trials because of its limited reproducibility, the large number of patient's cells, the expense, the technical expertise, and the significant labor required [33]. Considering these limitations, PCR-based methods were developed to provide upper limit estimates of HIV reservoirs, as an easier, cheaper and less error-prone tool that might compliment QVOA.

In the following paragraphs, we describe some scenarios where integrated HIV DNA provided unique insights about reservoir characterization, in settings where other assays could not be fully exploited because of the presence of unintegrated HIV DNA, ongoing replication (untreated infection, episodes of viremia on ART) or because of limited cell availability (studies on HIV persistence in cellular subsets).

\section{Integrated HIV DNA in cellular subsets}

In the last 20 years, the HIV field has progressively gained a better understanding of the cellular subsets contributing to the reservoir size. Ostrowski et al. [15] showed that memory CD4 $\mathrm{T}$ cells contain 16-fold more integrated HIV DNA than naive cells consistent with the idea that the memory CD4 $\mathrm{T}$ cells make up the largest portion of the HIV reservoir. However, the difference between memory and naive cells (defined as CD62L + CD45RA + cells) was much smaller in patients infected with C-X-C chemokine receptor type 4 (CXCR4) viruses. This could be explained by the near absence of $\mathrm{C}-\mathrm{C}$ chemokine receptor type 5 (CCR5) and high levels of CXCR4 in naive cells. Similarly, Chomont et al. [34] showed that the pool of cells containing integrated HIV DNA is mostly represented by cells with a memory phenotype. Measurements of integration provided important evidence suggesting that naive $T$ cells contribute to the reservoir, which were then confirmed in a small subset of patients by QVOA as well $[15,34,35]$. Given the long intermitotic half-life of naive $\mathrm{T}$ cells, this subset may prove to be a significant under-investigated barrier to cure and integration measurements remain the primary evidence of their contribution to the reservoir. Notably, this data should be evaluated in light of recent studies on 
T memory stem cells (TSCM) [36-39], which are phenotypically similar to naive $\mathrm{T}$ cells, but can be distinguished by the expression of CD95 and interleukin 2 receptor subunit beta. Considering the long half-life of naive and TSCM, both cell subsets could be significant contributors to the reservoir.

Central memory (TCM, CD45RA-CCR7+CD27+) and transitional memory (TTM, CD45RA-CCR7-CD27+) CD4 T cells contain the majority of integrated HIV DNA, and could be responsible for reservoir maintenance/ replenishment through several mechanisms, including antigen-driven and homeostatic proliferation. TCM were reported to be the main reservoir in immunological responders and individuals who started treatment early. On the other end of spectrum, in patients with low CD4 $\mathrm{T}$ cell counts the majority of HIV DNA was harboured by TTM. These cells have increased proliferative activity in comparison to TCM and may therefore contribute to the stability of the reservoir. The reservoir size was smaller in individuals with higher CD4 nadir, higher absolute CD4 counts and a CD4/CD8 $>1$. Moreover, integrated HIV levels were significantly lower in patients who had started ART within the first year of infection [34].

Recent studies have provided an in-depth phenotypical analysis of cellular subsets that can be enriched for HIV DNA. Gosselin et al. [40] sorted blood memory cells according to the expression of CCR6, CCR4 and CXCR3 to differentiate the following subsets: $\mathrm{T}$ helper (Th)17 (CCR4 + CCR6+), Th2 (CCR4 + CCR6-), Th1Th17 (CXCR3 + CCR6+), and Th1 (CXCR3 + CCR6-). These subsets showed different susceptibility to HIV infection in vitro: in fact, cells with a Th17 and Th1Th17 profile appeared highly permissive to R5 and X4 HIV infection, whereas those with a Th2 profile were susceptible to X4 HIV replication only, and cells with a Th1 profile were relatively resistant to both R5 and X4 HIV replication. There was an enrichment for integrated HIV DNA in circulating CCR6 + T cells of HIV-infected subjects, both off and on ART, but a parallel depletion of these cells in comparison to uninfected controls, suggesting they may be preferentially infected and killed by HIV. Since the CCR6/C-C motif ligand-20 (CCL20) axis is important for mucosal homeostasis, more CCR6 + cells can potentially be recruited in tissues, such as the gut, the vagina and the brain, attracting additional susceptible cells at the sites of viral replication. The same group showed more recently that CCR6 + cells are enriched in the colon of individuals on ART in comparison to blood. Moreover, in both compartments CCR6 + cells harbour higher levels of total HIV DNA in comparison to CCR6- cells [41]. An enrichment for integrated DNA in CXCR3 + CCR6+ cells has been reported by others [42].
Immune checkpoint molecules are co-inhibitory receptors, physiologically involved in the containment of immune activation. Overexpression of several immune checkpoint molecules has been associated with $\mathrm{T}$ cell exhaustion and dysfunction. A recent study evaluated their association with HIV reservoir size [43]. In patients on stable ART, none of the markers alone was associated with integrated HIV DNA when adjusting for current CD4 count. However, the co-expression of Lymphocyte activation gene-3 (LAG-3), T cell Immunoglobulin and ITIM domain (TIGIT), and Programmed death-1 (PD-1) correlated with the frequency of cells harbouring integrated HIV DNA, after adjusting for nadir and current CD4 T cell count $(p=0.038)$. Memory CD4 T cells showed a gradual enrichment for integrated HIV DNA when expressing an increasing number of immune checkpoint molecules. Cells expressing the 3 markers were eightfold enriched for integrated HIV DNA in comparison to the whole CD4 population. The authors speculated that cells expressing these markers can be preferentially infected with HIV, or they may preferentially persist in comparison to the negative ones.

\section{Dynamics of integrated HIV DNA in acute and chronic HIV infection}

The first hint that treating patients early would be more effective at reducing reservoir size came from Strain et al. [44]. They showed that after one year of ART replicationcompetent HIV could not be detected by QVOA in any of the individuals starting ART during primary HIV infection (PHI) and in the majority of patients initiating therapy within 6 months after seroconversion.

Recent studies of the dynamics of integrated HIV DNA provide some clues to possible mechanisms behind restriction of reservoir size with early treatment including immune clearance. Both animal and human models have shown that HIV seeding occurs very early during HIV infection [45-47]. However, there is evidence that the earlier ART is started during acute infection the smaller the HIV reservoir is after virological suppression [48]. An in-depth study of acutely infected subjects in Thailand evaluated the dynamics of total, 2-Long Terminal Repeat (LTR) and integrated HIV DNA in untreated and treated acute HIV infection [49]. In untreated patients (Fiebig stage I/II (HIV RNA+, p24 \pm , HIV IgM-)), integrated HIV DNA peaked at week 2 after enrollment, declined significantly between week 2 and week 6 , and then gradually increased over time. By the end of the observation period (week 144), integration levels were significantly higher than at nadir $(p=0.02)$. Total HIV DNA did not capture this effect, likely because of the excess of unintegrated DNA: it increased rapidly, peaking at week 2 , but did not change significantly afterwards in the untreated 
group. Treated individuals started ART immediately after enrollment (46\% in Fiebig stage I/II). Integrated HIV DNA was 25-fold lower at week 2 and 100-fold lower at week 144 in comparison to untreated individuals. These findings have important clinical implications, since both total and integrated HIV DNA measures correlate with immune reconstitution, with immune activation and predict the time to viral rebound after ART interruption [50-53]. Thus, in certain settings integrated HIV DNA can be a correlate of reservoir size, despite the fact that it is an overestimate and has additional limitations discussed below.

Several studies have shown that initiating ART during acute infection is associated with a greater decline in the levels of integrated HIV DNA [54-56]. A limitation of these studies is their small size, but the consistent finding from all three groups that integrated HIV DNA was cleared more rapidly and effectively if patients were treated early makes these results more convincing. Murray et al. [56] showed the decline of integrated HIV DNA was biphasic and that the first phase of decay was significantly faster when patients were treated early after HIV infection with a half-life of 10 versus 43 days for the first phase of decay $(p=0.04)$ and then 63 versus 172 days. Meanwhile the rate of decay for total HIV was similar for both groups. Pinzone et al. showed that acutely infected individuals exhibited a significant drop in integrated HIV levels 12 months after ART initiation, while integration levels barely changed in patients treated during chronic infection [54], consistent with Koelsch et al. [55]. Moreover, Buzon et al. [57] found treating the earliest stages Fiebig III/IV resulted in a larger drop in integrated HIV DNA than treating in Fiebig V; uniquely, the decline in integrated HIV continued in those patients treated at the very earliest stages over several years. Pre-ART integration levels also correlated with viral load $(\mathrm{r}=0.86)$ and negatively correlated with $\mathrm{CD} 4 / \mathrm{CD} 8$ ratio $(\mathrm{r}=-0.52)$, consistent with the idea that integrated HIV DNA can provide a surrogate marker for reservoir size [54] and consistent with [34, 56, 58]. These longitudinal studies highlight that integrated HIV DNA measures provide different and complementary information to total HIV DNA when an excess of unintegrated HIV DNA may exist.

Potential reasons for lower reservoirs when initiating ART early include (1) less escape from cytotoxic T lymphocyte (CTL) [59, 60], (2) more functional CTL during acute infection $[59,61,62]$, (3) preferential protection of TCM [50,63] and (4) increased susceptibility to ART. The latter possibility would seem likely if the fraction of HIV harbouring replication-competent proviruses is larger in acute infection. A limitation of these studies is the lack of information on the fraction of proviruses that are replication-competent. If replication-competent proviruses plateau early after infection, then the reduction in integration levels observed in acute infection is likely to reflect the effectiveness of ART against replication-competent proviruses while in individuals with chronic infection the majority of proviruses are defective and only a small fraction of them will be cleared by antiretroviral drugs. If replication-competent proviruses continue to accrue at a constant rate, this would suggest that the immune system is more effective early after HIV infection. Bruner et al. [64] have recently provided the first attempt to characterize the proviral landscape by sequencing proviruses during acute infection. The authors showed that defective proviruses accumulate early in HIV infection, making up over $93 \%$ of the proviral pool, even when ART is started within the first 2-3 weeks from enrolment. Alternatively, it is possible that a significant fraction of the reservoir is expressed and potentially cleared even in individuals treated during chronic infection, but the clonal expansion of defective clones may mask a drop in reservoir size by DNA measures [65]. Sequencing proviruses at multiple time points could provide new insights on the dynamics of intact/ defective proviruses over time.

\section{Longitudinal studies show integrated HIV DNA increases over time}

In the absence of ART, integrated HIV DNA accumulates over time after a brief decline that may be immune-mediated [49, 54]. Pinzone et al. [54] monitored longitudinally integrated HIV DNA in 6 individuals followed from acute to chronic infection (mean observation time 6 years), showing that integrated HIV DNA increased progressively over time (from 109 to 1941 copies/million peripheral blood mononuclear cells (PBMCs)). The authors compared the increase in reservoir size observed in chronic progressors (CPs) versus long-term nonprogressors (LTNPs). As expected [57, 66], they found that LTNPs have much lower integrated HIV DNA levels. However, in the absence of ART LTNPs experienced an increase in the levels of integrated HIV DNA over time (from 17 to 34 copies/million PBMCs over 5 years), consistent with evidence of ongoing replication [67-69]. Integration levels did not significantly change in ART controls. Among the chronic progressors, the rate of integration increase varied greatly; in fact, two patients showed some decline in integrated HIV DNA within the first 2 years of observation, followed by an increase in integration levels, suggesting that some transient immune control existed early during infection. The different accumulation rate observed in LTNPs and chronic individuals can be due to differences in CTL functions. However, loss of CTL function over time did not explain 
the increase in integrated HIV DNA in LTNP patients as CTL function did not decline over time. We speculate that reservoir expansion could be due to ongoing viral replication in sanctuary sites, such as the B-cell follicles, where CD8 T cells are functionally excluded [70-72]. The increase in integrated HIV DNA over time suggests that the true reservoir size increases over time $[8,32]$.

\section{Structured Treatment Interruptions and integrated HIV DNA measures}

Several studies have evaluated the changes in total HIV DNA levels after ART interruption [52, 53, 73, 74], but few have addressed changes in integrated HIV DNA $[53,75]$. The VISCONTI cohort provides an example of enhanced frequency of functional cure for HIV, as a higher fraction of individuals who were started on ART within 2 months of infection were able to maintain undetectable viral loads for several years after ART withdrawal [50]. In the Spartac study and the ANRS 116 SALTO study, total HIV DNA levels were shown to be predictive of the timing of viral rebound in patients treated early after infection [52, 53]. Azzoni et al. showed in a small pilot study of patients on ART who received treatment intensification with pegylated interferon alpha-2a $($ IFN- $\alpha-2 a)$ that integrated HIV DNA actually declined after treatment interruption in the subset of patients that maintained virologic control [51]. More data on the kinetics of integration levels coupled with proviral sequencing after STI would improve our understanding of reservoir expansion in this setting.

\section{Integrated HIV DNA and reservoir clearance}

Integrated HIV DNA can be an useful tool to assess CTL-mediated clearance of infected CD4 T cells [76]. Graf et al. measured the levels of integrated and 2-LTR intermediates in CD4 $\mathrm{T}$ cells from LTNPs that had been superinfected in vitro and cocultured with autologous CD8 $\mathrm{T}$ cells. They showed the preferential clearance of integrated over 2-LTR DNA in the presence of CTL. This was consistent with the hypothesis that Gag+ cells are preferentially cleared, since integrated HIV but not 2-LTR expresses Gag in an efficient manner under short-term coculture [77]. The authors also found that integrated HIV DNA inversely correlated with CTL capability to clear infected cells both in LTNPs and CPs. These findings again are consistent with the idea that CTL activity controls the expansion of HIV reservoirs and at least in the very early stages of infection immune clearance plays a role in limiting reservoir size.

Integration measures have helped capture the possible role of immune clearance in reservoir formation and maintenance. In fact, in the setting of untreated infection other assays, such as total HIV DNA or QVOA, cannot be used to assess the dynamics of reservoir change over time. In the aforementioned study from the acute Thailand cohort [49] the drop in integrated HIV DNA between week 2 and 6 suggests clearance, possibly immune-mediated, of infected cells. Similarly, in the study from Buzon et al. [57] patients starting therapy in the earliest Fiebig stages did have smaller reservoirs. In [54], some chronic progressors did show an initial contraction of the reservoir during the acute phase of infection, followed by reservoir expansion, suggestive of initial immune control, which was then lost over time.

\section{Integrated HIV DNA in studies using latency reversal agents (LRAs)}

A few trials have evaluated the change in integrated HIV DNA levels after the administration of LRAs to disrupt latency, such as vorinostat [78], panobinostat [79], and romidepsin [80]. Interestingly, in none of these studies a significant change in integration levels was found at a cohort level. This could be due to the fact that only a minority of patients may respond to the intervention and the change in their reservoir size can be masked when looking at the average response in the cohort. Moreover, at an individual level, defective proviruses that contain no open reading frames (ORFs) would not be cleared by eradication strategies, and if such proviruses were prominent they would mask clearance in the population of intact proviruses. Since some studies only target one ORF (HIV Gag in the Vacc4x study) [80], only intact proviruses and proviruses expressing Gag would be expected to be cleared with this approach, resulting in only small changes in HIV integration (in most cases < twofold). Notably, one patient in Vacc4x study did show a reduction in integrated and total HIV DNA and QVOA, and may represent a responder [80]. Follow-up studies sequencing proviruses in this potential responder may clarify if the patient is a true responder. One potential advantage of measuring integrated HIV DNA is that the error of the assay is low and this makes it possible to identify a small reduction in individual responders by monitoring the patients longitudinally. While total HIV DNA measurements also have a small error, we speculate many therapeutic approaches, especially LRAs, have the potential to induce a round of reverse transcription (unpublished data). In this case, total HIV DNA might not capture a reduction in the size of the reservoir, which could be detected by integrated HIV DNA [81].

\section{Combined use of HIV DNA intermediates to model the dynamics of reservoir over time}

In some studies, mathematical modelling has provided important insights into how different HIV intermediates in resting and activated cells change over time on ART. 
Murray et al. [58] analyzed longitudinally the dynamics of HIV intermediates in resting and activated cells of 8 patients with acute infection and 8 patients with chronic HIV starting an antiretroviral regimen containing raltegravir.

Before ART initiation, resting cells had the highest levels of 2-LTR and 2-LTR/integrated HIV DNA ratio. These observations are consistent with direct infection of resting cells in vivo [16-25], as supported by recent modelling [82]. 2-LTR would be expected to accumulate in resting cells as a consequence of the longer life span of resting cells as well as less efficient integration in resting cells $[18,19,83]$.

Interestingly, after 1 year of ART, the levels of total, integrated and 2-LTR DNA were similar in resting and activated cells. This has important implications for eradication studies. At first blush, we would expect HIV DNA levels to quickly decline in activated cells after starting ART, if ongoing replication were stopped [84], as a result of several mechanisms, including cell death due to viral cytotoxicity. However, the persistence of HIV DNA in activated $\mathrm{T}$ cells suggest that cells may be converting from a resting to an activated phenotype and vice versa. This, in turn, suggests that activation of an HIV infected cells does not always result in cell death before the cell can return to a resting state. This, in turn, suggests the basic idea of "shock and kill" may be more difficult to achieve than initially thought since cell activation from latency may not result in cell death.

\section{Integrated HIV DNA: technical aspects}

\section{Principles of the assay}

HIV integration is measured using a nested real-time approach $[85,86]$. The first step of PCR anchors a forward primer to the human Alu element and a reverse primer to the HIV genome. Alu is a repeat element in the human genome that occurs approximately every 3,000 base pairs. Only integrated HIV DNA is exponentially amplified by the first step, whereas unintegrated HIV DNA is linearly amplified by the HIV primer since only one strand can be copied. The second step is a real-time PCR approach within the HIV LTR. In order to adjust for the amount of unintegrated HIV DNA that can be linearly amplified, during the first step some wells contain only the HIV-specific primer. This controls for the background signal coming from unintegrated HIV and is used to define a threshold for a signal that represents a positive well for integration. Alu-HIV PCR is the most applied method to measure integrated HIV DNA. Less common methods include inverse PCR, linker ligation PCR and gel separation $[10,87,88]$.

In the gel separation method, DNA samples are run on a gel to separate genomic high-molecular weight
DNA from episomal DNA. The genomic DNA recovered from the gel is then used to measure HIV DNA by PCR. Recently, Lada et al. used pulse-field gel electrophoresis combined with droplet digital PCR, and showed good correlation with Alu-HIV PCR ( $\mathrm{r}=0.7, p=0.023)$, and efficient removal of unintegrated forms, but low yields from the gel (on average 21\%) [87].

\section{Choice of the PCR primers}

Different labs measuring integrated HIV DNA use different HIV primers for the first amplification step. O'Doherty's lab uses a primer located in a conserved region of the Gag gene (primer SK431). Chomont's lab uses a primer annealing in the U3-R junction of the LTR [89]. The difference in primers used for the first step has important implications, as in the first case only proviruses containing an intact Gag region will be amplified, while with the second primer all the proviruses with an intact LTR will likely be amplified, including a larger number of massively deleted proviruses. One primer may have advantages over the other, depending on the specific experimental question that is being asked. For example, in studies evaluating reservoir clearance after priming for Gag CTL, the Gag primer may be preferred, as in that case integrated HIV decline may represent a surrogate of reservoir contraction. On the other hand, the AluLTR assay will capture all the integrated HIV DNA and therefore provides increased sensitivity over Alu-Gag. This could be an important advantage in the assessment of reservoir changes after therapeutic interventions (for instance bone marrow transplantation), when the levels of residual HIV DNA are expected to be extremely low and a very sensitive assay is required to detect any residual HIV.

\section{Quality control for robust measurements}

Consistency of amplification is affected by variations in master mixes, Taq polymerase, as well as variability between thermocyclers. Large volume PCR master mixtures minimize systematic variation. An integration standard can be included in all runs to test thermocycler conformity from run to run and to identify PCR inhibition (by adding the standard to patient samples) $[9,85]$. Some laboratories utilize serial dilutions of cell lines (e.g. $\mathrm{ACH}-2$ ) to create a standard curve to quantify integrated HIV DNA [89]. The ACH-2 cells are not entirely transcriptionally silent and contain variable numbers of HIV integrations (from 5 to 10 in our hands) [90]. Every lab should verify the number of proviruses per cell in a given lot of $\mathrm{ACH}-2$ cells before using them as a standard in these assays. This is actually an advantage for the $\mathrm{ACH}-2$ cells line, as it has sufficient diversity of integration sites to roughly capture the diversity of distances to Alu 
present in acute infection and can be used to estimate integration frequency while other cell lines with 1-2 proviruses do not provide strong estimates.

For each infected cell, the distance between the integrated provirus and the nearest $A l u$ element is variable. Therefore, each provirus will be amplified at different efficiency depending on its distance from the closest $\mathrm{Alu}$ [17]. This represents an important limitation of the assay, which is mitigated by repetitive sampling. Moreover, to reduce variability between runs as well as variability between different laboratories, our laboratory currently measures integrated HIV DNA using the Poisson distribution. This allows the quantification of integrated HIV DNA without using a standard curve. We target 30-80\% of positive wells at two dilutions in a 96-well plate to obtain the most robust result, as error increases outside of this range. This implies that we need $\sim 500$ proviruses per patient to obtain a robust measure of the integration levels [unpublished data]. It follows that the number of cells required for the assay will largely vary depending on the individual integration levels. The chance that the well contains no integrated HIV DNA (negative reaction) or 1 or more proviruses (positive reaction) will follow the Poisson distribution. The number of copies of integrated HIV can be calculated from the frequency of positive wells by PCR without the need of a standard curve [91], though we do apply a correction factor as our assay detects $\sim 10 \%$ of integrations [91] (20\% of integrations are detected with recent improvements due to decreased gag background).

Measuring integrated HIV DNA robustly in LTNPs is challenging. It requires a large number of cells, as in some patients the integration level may be as low as 1-5 copies/million PBMCs, which can be a limitation if apheresis products are not available [66]. To increase the sensitivity of the assay, a large number of cells per well are needed, and this requires best-quality DNA in order to avoid PCR inhibition.

Some labs compensate for limited numbers of available cells by testing large numbers of patients [89]. However, a low number of repeats reduces the sensitivity of the assay, which implies that negative results should be interpreted carefully, as they may reflect the limited quantity of cells tested.

\section{Measuring integrated HIV DNA: a summary of pros and cons Strengths}

On a technical level, integrated HIV DNA is relatively inexpensive, robust, and potentially high-throughput in comparison to QVOA. Total and integrated HIV DNA can be combined to capture ongoing replication. A full review of total HIV DNA as a measure of reservoir size is provided in another chapter of this special issue [92]. In patients on long-term ART, integration levels are relatively similar to total HIV DNA and consistent with a relatively stable reservoir $[34,81]$. Total and integrated HIV DNA provide different insights [93]. Total DNA showed a similar decline in acute and chronic infection with a sevenfold decline in the first year and a slower decline over the next few years from pre-ART levels [93]. In contrast, there was a tenfold decline of integrated HIV DNA levels in acute infection, whereas there was only a twofold decline in patients treated chronically [54].

Mexas et al. [81] showed the utility of combining total and integrated HIV DNA in clinical trials. In the presence of detectable viremia, the authors showed an increase in the ratio between total and integrated HIV. Moreover, they evaluated the change in reservoir size of patients on stable ART who received IFN- $\alpha-2 a+$ ART for 5 weeks, followed by IFN- $\alpha-2$ a alone for 12 weeks. $45 \%$ of patients maintained a viral load $<400$ copies/ml during ART interruption and were considered "responders". Treatment with IFN- $\alpha-2 \mathrm{a}$ led to an increase in total over integrated HIV DNA as well as an increase in viremia on ART and after ART interruption, suggesting that IFN$\alpha-2 a$ treatment induced ongoing replication. In responders, the administration of IFN- $\alpha-2$ a also led to a decrease in integrated but not total HIV DNA levels. This discrepancy between total and integrated HIV DNA could be due to the imbalance between the immune-mediated clearance of cells containing integrated HIV (reduction in integration levels) and de novo infection of new cells (increase in total DNA). These results suggest that the concomitant use of total and integrated HIV DNA can provide insights into the changes in reservoir size after therapeutic interventions.

Moreover, in some cases total HIV DNA cannot be used to measure reservoir size. In most patients off ART unintegrated HIV represents the most abundant form. In those cases, total HIV DNA measures would be largely driven by variable levels of linear and circular non-integrated forms. Therefore, integrated HIV DNA can represent a more appropriate tool to measure reservoir size in patients off ART.

Integrated HIV DNA is a robust assay, and can capture smaller changes than the QVOA assay. Integration levels correlated with QVOA in a comparative study of reservoir assays [33] ( $\mathrm{r}=0.7, p=0.0008)$. In this study, QVOA did not correlate with total HIV DNA, probably because of data censoring; a few samples were negative for total HIV DNA by digital droplet PCR, thus reducing the strength of the correlation. Similarly, Mendoza et al. [94] reported that QVOA correlated with integrated HIV DNA in a cohort of LTNPs $(\mathrm{r}=0.72, p=0.03)$. More recently, similar findings were published by Kiselinova 
et al. [95] in a cohort of 25 long-term treated patients who started ART during chronic infection. The authors found that integrated HIV DNA correlated with total HIV DNA $\left(\mathrm{R}^{2}=0.85, p<0.001\right)$ and QVOA $\left(\mathrm{R}^{2}=0.44\right.$, $p=0.041)$. Thus, while integration is an overestimate of reservoir size and while the number of defective proviruses vary between patients, in some settings measuring integrated HIV DNA can serve as a less error-prone surrogate of reservoir size.

\section{Weaknesses: variable overestimate of reservoir size}

Most of the integrated HIV DNA is not replicationcompetent, as it contains large deletions, mutations originating from viral reverse transcriptase or from innate host defense mechanisms (e.g. APOBEC3G). PCR-based methods overestimate reservoir size as the majority of proviruses are defective in individuals on ART $[26,96]$. Those proviruses will not be distinguished from replication-competent ones using $\mathrm{Alu}$-HIV assays. Table 1 provides three possible outcomes of eradication trials when using integrated HIV DNA to assess if a therapy is effective. In scenario 1 , an intervention might be effective in reducing the "real" reservoir, but have no effect on defective proviruses such that integrated HIV DNA would remain unchanged. This might occur if clearance of the infected cells required virion release or if a strategy required high-level expression of Gag, which would require in turn expression of Tat and Rev; thus, these proviruses are generally largely intact and unlikely to be defective. In scenario 2 , an intervention that targets only defective proviruses would decrease the levels of integrated HIV DNA, but this drop would not reflect a decrease in the size of the "true" reservoir. This might occur if replication-competent proviruses are more resistant to transcription or translation than defective ones. possibly due to the repressive nature of the site of integration. In scenario 3, a decline in integration would likely capture a reduction in reservoir size if an intervention targets both defective and replicationcompetent proviruses, though the reduction would not likely capture the precise change in the true reservoir as defective and replication-competent proviruses are not expected to be targeted proportionally. This could occur if an immune therapy can clear both defective and replication-competent proviruses that are capable of expressing HIV proteins as was proposed to occur in [51, 81]. If transcription of replication-competent proviruses is not repressed more than transcription of defective proviruses, the immune response should be more effective at clearing replication-competent proviruses that defective ones, since replication-competent proviruses have 9 ORFs for the immune system to target. The previously mentioned IFN- $\alpha-2 a$ trial suggested this third scenario could occur. Given that IFN- $\alpha-2 a$ would likely increase immune clearance of all protein-expressing cells, it was likely that defective proviruses with intact ORFs as well as intact ones could both be cleared. Notably proviruses that contain no ORFs should not be cleared, though these represent a minority of proviruses [64, 97].

HIV integrates preferentially within regions of active transcription $[98,99]$. Alu repeats are also more prominent in gene-rich regions. As described, the integration standard was designed to correct for the tendency of HIV to integrate closer to Alu sites. However, this correction did not account for clonally expanded integration sites. With time on ART clonal expansion occurs [100] and there appears to be selection with a tendency for clones that are near cell cycle genes. In fact, it has been shown that after several years on ART more than $40 \%$ of proviruses are located in the genome of cells that have undergone clonal expansion after HIV integration. Clonal expansion may result from selection of proviruses integrated HIV preferential selection into genes promoting cell growth, as recently shown by Maldarelli et al. [101]. These genes also tend to be close to Alu sites. As a consequence, proviruses that are closer to Alu sequences are likely to be preferentially expanded over time on ART. Thus, the presence of clonal expansion can result in apparently higher levels of integrated HIV DNA over time in comparison to total HIV DNA

Table 1 Possible outcomes of eradication trials when using integrated HIV DNA to assess the change in reservoir size

\begin{tabular}{lc}
\hline Possible outcome in eradication studies & How does the outcome affect reservoir measures? \\
\hline 1. Preferential reduction in intact proviruses & $\begin{array}{c}\text { Integrated HV DNA is likely to be unchanged. Proviral sequencing would likely detect a reduction } \\
\text { in the fraction of replication-competent proviruses which could be combined with integration } \\
\text { measures to determine the absolute reduction in intact proviruses }\end{array}$ \\
$\begin{array}{ll}\text { 2. Preferential reduction in defective proviruses } & \text { Integrated HIV DNA would decrease, without reflecting a contraction in the size of the "true" reser- } \\
\text { voir. Proviral sequencing would likely capture the change in the fraction of defective proviruses }\end{array}$ \\
$\begin{array}{ll}\text { 3. Decrease in both intact and defective proviruses } \\
\text { If intact and defective proviruses are targeted differently, a decrease in integrated HIV DNA would } \\
\text { occur, but would not likely be proportional to the decrease in the number of intact proviruses. } \\
\text { Proviral sequencing combined with integration measures would likely capture the changes in } \\
\text { the reservoir size and character }\end{array}$
\end{tabular}


measures. Integration site analysis of patients with discrepant total and integration measurements may clarify why integration levels can appear to be slightly higher in some patients on ART. While clonal expansion is an appealing explanation for discrepancies between total and integrated HIV DNA, in our hands integrated and total HIV DNA are relatively constant over time on ART which is not consistent with this explanation. Regardless, the exact level is less important than the relative change for revealing reservoir expansion, contraction and ongoing replication.

There are some instances where knowing the exact level is important as well, for instance to estimate the total-body reservoir size. One scenario could be represented by STI after bone marrow transplantation, when the residual reservoir size is expected to be extremely low. In that case, the use of PCR assays, especially total HIV DNA, along with extensive sampling, likely represents the most sensitive tool to assess how much HIV persists in the body.

\section{Solutions to the hurdles involve combining integration measures with proviral sequencing}

Combining integration measures with proviral sequencing to identify intact proviruses may represent the best tool to estimate the size of the HIV reservoir, but the assay is expensive and labor-intensive, and requires considerable bioinformatics expertise, limiting its scalability in large cohorts. As more data accumulate on reservoir growth and decay, it may be possible to choose cohorts with similar reservoir size and sequence characteristics, in which case PCR measures of integration might be useful to identify responders to a therapy, but accurate measurement of reservoir reduction would likely involve sequencing as well.

\section{Conclusions}

Measuring HIV reservoirs robustly is still a challenge for the field. Every available marker has its own strengths and weaknesses. The choice of the most appropriate marker(s) depends on the experimental question that is being asked. Measuring integrated HIV DNA has increased our understanding of HIV dynamics but, as discussed, the assay has several limitations, which impose a careful use of this tool in clinical studies. Proviral sequencing combined with integration measurements will likely provide the closest estimate of reservoir size, and the most powerful tool to characterize and monitor the proviral landscape in HIV-infected individuals.

\section{Abbreviations}

ART: antiretroviral therapy; CXCR4: C-X-C chemokine receptor type 4; CCL20: C-C motif ligand 20; CCR5: C-C chemokine receptor type 5; CP: chronic progressor; CTL: cytotoxic T lymphocyte; CTLA-4: cytotoxic T-lymphocyteassociated protein-4; HIV: human immunodeficiency virus; IC: immune checkpoint molecule; IFN-a: interferon alpha; IUPM: infectious units per million cells; LAG-3: Iymphocyte activation gene-3; LN: Iymph node; LRA: latency reversal agent; LTNP: long-term nonprogressor; LTR: long terminal repeat; PBMC: peripheral blood mononuclear cell; PCR: polymerase chain reaction; PD-1: programmed death-1; PHI: primary HIV infection; ORF: open reading frame; STI: structured therapeutic interruption; TSCM: T memory stem cell; TCM: central memory T cell; TEM: effector memory T cell; Th: T helper; TIGIT: T cell Immunoglobulin and ITIM domain; TIM-3: T cell immunoglobulin-3; TTM: transitional memory $T$ cell; QVOA: quantitative viral outgrowth assay.

Authors' contributions

Both authors read and approved the final manuscript.

\section{Acknowledgements}

We would like to acknowledge Daniel J. VanBelzen for his many insights into the measurement of HIV integration that have further enhanced our ability to apply this assay to appropriate clinical questions.

\section{Competing interests}

The authors declare they have no competing interests.

Availability of data and materials

Not applicable.

Consent for publication

Not applicable.

Ethics approval and consent to participate

Not applicable.

Funding

R01-AI-120011; R33-AI-104280; UM1-Al-126617.

\section{Publisher's Note}

Springer Nature remains neutral with regard to jurisdictional claims in published maps and institutional affiliations.

Received: 2 November 2017 Accepted: 19 January 2018

Published online: 17 February 2018

References

1. Palella FJ Jr, Delaney KM, Moorman AC, Loveless MOFJ, Satten GA, Aschman DJHS. Declining morbidity and mortality among patients with advanced human immunodeficiency virus infection. HIV Outpatient Study Investigators. N Engl J Med. 1998;338:853-60.

2. Samji H, Cescon A, Hogg RS, Modur SP, Althoff KN, Buchacz K, et al. Closing the gap: increases in life expectancy among treated HIVpositive individuals in the United States and Canada. PLoS One. 2013;8(12):e81355. https://doi.org/10.1371/journal.pone.0081355.

3. Wada N, Jacobson LP, Cohen M, French A, Phair J, Muñoz A. Causespecific mortality among HIV-infected individuals, by CD4 + cell count at HAART initiation, compared with HIV-uninfected individuals. AIDS. 2014;28:257-65. https://doi.org/10.1097/QAD.0000000000000078.

4. Finzi D, Blankson J, Siliciano JD, Margolick JB, Chadwick K, Pierson T, et al. Latent infection of CD4 + T cells provides a mechanism for lifelong persistence of HIV-1, even in patients on effective combination therapy. Nat Med. 1999;5:512-7. https://doi.org/10.1038/8394.

5. Wong JK, Hezareh M, Günthard HF, Havlir DV, Ignacio CC, Spina CA, et al. Recovery of replication-competent HIV despite prolonged suppression of plasma viremia. Science. 1997;278:1291-5.

6. Siliciano JD, Kajdas J, Finzi D, Quinn TC, Chadwick K, Margolick JB, et al. Long-term follow-up studies confirm the stability of the latent reservoir for HIV-1 in resting CD4 + T cells. Nat Med. 2003;9:727-8. 
7. Laird GM, Eisele EE, Rabi SA, Lai J, Chioma S, Blankson JN, et al. Rapid quantification of the latent reservoir for HIV-1 using a viral outgrowth assay. PLoS Pathog. 2013;9:e1003398. https://doi.org/10.1371/journal. ppat.1003398.

8. Avettand-Fènoë V, Hocqueloux L, Ghosn J, Cheret A, Frange P, Melard A, et al. Total HIV-1 DNA, a marker of viral reservoir dynamics with clinical implications. Clin Microbiol Rev. 2016;29:859-80.

9. Graf EH, O'Doherty U. Quantitation of integrated proviral DNA in viral reservoirs. Curr Opin HIV AIDS. 2013;8:100-5. https://doi.org/10.1097/ COH.0b013e32835d8132.

10. Chun TW, Finzi D, Margolick J, Chadwick K, Schwartz D, Siliciano RF. In vivo fate of HIV-1-infected T cells: quantitative analysis of the transition to stable latency. Nat Med. 1995;1:1284-90.

11. Chun TW, Stuyver L, Mizell SB, Ehler LA, Mican JA, Baseler M, et al. Presence of an inducible HIV-1 latent reservoir during highly active antiretroviral therapy. Proc Natl Acad Sci USA. 1997;94:13193-7. https:// doi.org/10.1073/pnas.94.24.13193.

12. Bukrinsky MI, Stanwick TL, Dempsey MP, Stevenson M. Quiescent T lymphocytes as an inducible virus reservoir in HIV-1 infection. Science. 1991;254:423-7. https://doi.org/10.1126/science.1925601.

13. Korin YD, Zack JA. Progression to the G1 b phase of the cell cycle is required for completion of human immunodeficiency virus type 1 reverse transcription in T cells. J Virol. 1998;72:3161-8.

14. Stevenson M, Stanwick TL, Dempsey MP, Lamonica CA. HIV-1 replication is controlled at the level of T cell activation and proviral integration. EMBO J. 1990;9:1551-60. http://www.pubmedcentral.nih.gov/articlerender.fcgi?artid $=551849 \&$ tool $=$ pmcentrez\&rendertype $=$ abstract

15. Ostrowski MA, Chun TW, Justement SJ, Motola I, Spinelli MA, Adelsberger J, et al. Both memory and CD45RA +/CD62L + naive CD4(+) $T$ cells are infected in human immunodeficiency virus type 1-infected individuals. JVirol. 1999;73:6430-5.

16. Agosto LM, Yu JJ, Dai J, Kaletsky R, Monie D, O’Doherty U. HIV-1 integrates into resting CD4 + T cells even at low inoculums as demonstrated with an improved assay for HIV-1 integration. Virology. 2007:368(1):60-72.

17. Agosto LM, Yu JJ, Dai J, Kaletsky R, Monie D, O'Doherty U. HIV-1 integrates into resting $C D 4+T$ cells even at low inoculums as demonstrated with an improved assay for HIV-1 integration. Virology. 2007;368:60-72.

18. Pace MJ, Graf EH, Agosto LM, Mexas AM, Male F, Brady T, et al. Directly infected resting CD4 + T cells can produce HIV gag without spreading infection in a model of HIV latency. PLoS Pathog. 2012;8:e1002818. https://doi.org/10.1371/journal.ppat.1002818.

19. Plesa G, Dai J, Baytop C, Riley JL, June CH, O'Doherty U. Addition of deoxynucleosides enhances human immunodeficiency virus type 1 integration and 2LTR formation in resting CD4 + T cells. J Virol. 2007;81:13938-42. https://doi.org/10.1128/JVI.01745-07.

20. Swiggard WJ, Baytop C, Yu JJ, Dai J, Li C, Schretzenmair R, et al. Human immunodeficiency virus type 1 can establish latent infection in resting CD4 + T cells in the absence of activating stimuli. J Virol. 2005;79:14179-88. https://doi.org/10.1128/JVl.79.22.14179-14188.2005.

21. Chavez L, Calvanese V, Verdin E. HIV latency is established directly and early in both resting and activated primary CD4 T cells. PLoS Pathog. 2015;11:e1004955. https://doi.org/10.1371/journal.ppat.1004955.

22. Vatakis DN, Bristol G, Wilkinson TA, Chow SA, Zack JA. Immediate activation fails to rescue efficient human immunodeficiency virus replication in quiescent CD4 + T cells. J Virol. 2007;81:3574-82. https://doi. org/10.1128/JVI.02569-06

23. Saleh S, Solomon A, Wightman F, Xhilaga M, Cameron PU, Lewin SR. CCR7 ligands CCL19 and CCL21 increase permissiveness of resting memory CD4 + T cells to HIV-1 infection: a novel model of HIV-1 latency. Blood. 2007;1 10:4161-4

24. Dahabieh MS, Ooms M, Simon V, Sadowski I. A doubly fluorescent HIV-1 reporter shows that the majority of integrated HIV-1 is latent shortly after infection. J Virol. 2013;87:4716-27. https://doi.org/10.1128/ JVI.03478-12.

25. Lassen KG, Hebbeler AM, Bhattacharyya D, Lobritz MA, Greene WC. A flexible model of HIV-1 latency permitting evaluation of many primary CD4 T-cell reservoirs. PLoS One. 2012;7:e30176.

26. Ho Y-C, Shan L, Hosmane NN, Wang J, Laskey SB, Rosenbloom DIS, et al. Replication-competent noninduced proviruses in the latent reservoir increase barrier to HIV-1 cure. Cell. 2013;155:540-51. https://doi. org/10.1016/j.cell.2013.09.020.

27. Dar RD, Hosmane NN, Arkin MR, Siliciano RF, Weinberger LS. Screening for noise in gene expression identifies drug synergies. Science. 2014;344:1392-6. https://doi.org/10.1126/science.1250220.

28. Hiener B, Horsburgh BA, Eden J-S, Barton K, Schlub TE, Lee E, et al. Identification of genetically intact HIV-1 proviruses in specific CD4 + T cells from effectively treated participants. Cell Rep. 2017;21:813-22. https:// doi.org/10.1016/j.celrep.2017.09.081.

29. Soriano-Sarabia N, Bateson RE, Dahl NP, Crooks AM, Kuruc JD, Margolis DM, et al. Quantitation of replication-competent HIV-1 in populations of resting CD4 + T cells. JVirol. 2014;88:14070-7. https://doi. org/10.1128/JVI.01900-14.

30. Persaud D, Gay H, Ziemniak C, Chen YH, Piatak M, Chun T-W, et al. Absence of detectable HIV-1 viremia after treatment cessation in an infant. N Engl J Med. 2013;369:1828-35. https://doi.org/10.1056/ NEJMoa1302976.

31. Henrich TJ, Hu Z, Li JZ, Sciaranghella G, Busch MP, Keating SM, et al. Long-term reduction in peripheral blood HIV type 1 reservoirs following reduced-intensity conditioning allogeneic stem cell transplantation J Infect Dis. 2013;207:1694-702.

32. Henrich TJ, Hanhauser E, Marty FM, Sirignano MN, Keating S, Lee $\mathrm{TH}$, et al. Antiretroviral-free HIV-1 remission and viral rebound after allogeneic stem cell transplantation: report of 2 cases. Ann Intern Med. 2014;161:319-27.

33. Eriksson S, Graf EH, Dahl V, Strain MC, Yukl SA, Lysenko ES, et al. Comparative analysis of measures of viral reservoirs in HIV-1 eradication studies. PLoS Pathog. 2013;9:e1003174.

34. Chomont N, El-Far M, Ancuta P, Trautmann L, Procopio FA, Yassine-Diab $B$, et al. HIV reservoir size and persistence are driven by $T$ cell survival and homeostatic proliferation. Nat Med. 2009;15:893-900. https://doi. org/10.1038/nm.1972

35. Pierson T, Hoffman TL, Blankson J, Finzi D, Chadwick K, Margolick JB, et al. Characterization of chemokine receptor utilization of viruses in the latent reservoir for human immunodeficiency virus type 1. J Virol. 2000;74:7824-33. https://doi.org/10.1128/JVl.74.17.7824-7833.2000.

36. Tabler CO, Lucera MB, Haqqani AA, McDonald DJ, Migueles SA, Connors $M$, et al. CD4 + memory stem cells are infected by HIV-1 in a manner regulated in part by SAMHD1 expression. J Virol. 2014;88:4976-86. https://doi.org/10.1128/JVI.00324-14.

37. Buzon MJ, Sun H, Li C, Shaw A, Seiss K, Ouyang Z, et al. HIV-1 persistence in CD4 + T cells with stem cell-like properties. Nat Med. 2014;20:139-42. https://doi.org/10.1038/nm.3445.

38. Jaafoura S, de Herve MDG, Hernandez-Vargas EA, Hendel-Chavez $\mathrm{H}$, Abdoh M, Mateo MC, et al. Progressive contraction of the latent HIV reservoir around a core of less-differentiated $\mathrm{CD} 4^{+}$memory T Cells. Nat Commun. 2014;5:5407. https://doi.org/10.1038/ncomms6407.

39. Chahroudi A, Silvestri G, Lichterfeld M. T memory stem cells and HIV: a long-term relationship. Curr HIV/AIDS Rep. 2015;12:33-40.

40. Gosselin A, Monteiro P, Chomont N, Diaz-Griffero F, Said EA, Fonseca S, et al. Peripheral blood CCR4 + CCR6 + and CXCR3 + CCR6 + CD4 + T cells are highly permissive to HIV-1 infection. J Immunol. 2010;184:1604-16. https://doi.org/10.4049/jimmunol.0903058.

41. Gosselin A, Wiche Salinas TR, Planas D, Wacleche VS, Zhang Y, Fromentin $R$, et al. HIV persists in CCR6 + CD4 + T cells from colon and blood during antiretroviral therapy. Aids. 2017;31:35-48. https://doi.org/10.1097/ QAD.0000000000001309.

42. Khoury G, Anderson JL, Fromentin R, Hartogensis W, Smith $M Z$, Bacchetti $P$, et al. Persistence of integrated HIV DNA in CXCR3 + CCR6 + memory CD4 + T-cells in HIV-infected individuals on antiretroviral therapy. Aids. 2016. https://doi.org/10.1097/ QAD.0000000000001029.

43. Fromentin R, Bakeman W, Lawani MB, Khoury G, Hartogensis W, DaFonseca S, et al. CD4 + t cells expressing PD-1, TIGIT and LAG-3 contribute to HIV persistence during ART. PLoS Pathog. 2016;12:e1005761. https:// doi.org/10.1371/journal.ppat.1005761.

44. Strain MC, Little SJ, Daar ES, Havlir DV, Günthard HF, Lam RY, et al. Effect of treatment, during primary infection, on establishment and clearance of cellular reservoirs of HIV-1. J Infect Dis. 2005;191:1410-8. https://doi. org/10.1086/428777. 
45. Chun TW, Engel D, Berrey MM, Shea T, Corey L, Fauci AS. Early establishment of a pool of latently infected, resting CD4(+) T cells during primary HIV-1 infection. Proc Natl Acad Sci USA. 1998;95:8869-73. https:// doi.org/10.1073/pnas.95.15.8869.

46. Nishimura Y, Sadjadpour R, Mattapallil JJ, Igarashi T, Lee W, BucklerWhite $A$, et al. High frequencies of resting CD4 $+T$ cells containing integrated viral DNA are found in rhesus macaques during acute lentivirus infections. Proc Natl Acad Sci. 2009;106:8015-20. https://doi. org/10.1073/pnas.0903022106.

47. Whitney JB, Hill AL, Sanisetty S, Penaloza-MacMaster P, Liu J, Shetty M, et al. Rapid seeding of the viral reservoir prior to SIV viraemia in rhesus monkeys. Nature. 2014;512:74-7. https://doi.org/10.1038/nature13594.

48. Ananworanich J, Schuetz A, Vandergeeten C, Sereti I, de Souza M, Rerknimitr R, et al. Impact of multi-targeted Antiretroviral treatment on gut $T$ cell depletion and HIV reservoir seeding during acute HIV infection. PLoS ONE. 2012;7:e33948. https://doi.org/10.1371/journal. pone.0033948.

49. Ananworanich J, Chomont N, Eller LA, Kroon E, Tovanabutra S, Bose $M$, et al. HIV DNA set point is rapidly established in acute HIV infection and dramatically reduced by early ART. EBioMedicine. 2016;11:68-72. https://doi.org/10.1016/j.ebiom.2016.07.024.

50. Sáez-Cirión A, Bacchus C, Hocqueloux L, Avettand-Fenoel V, Girault t, Lecuroux C, et al. Post-Treatment HIV-1 controllers with a long-term virological remission after the interruption of Early initiated antiretroviral therapy ANRS VISCONTI study. PLoS Pathog. 2013;9:e1003211.

51. Azzoni L, Foulkes AS, Papasavvas E, Mexas AM, Lynn KM, Mounzer K, et al. Pegylated interferon alfa-2a monotherapy results in suppression of HIV type 1 replication and decreased cell-associated HIV DNA integration. J Infect Dis. 2013;207:213-22.

52. Assoumou L, Weiss L, Piketty C, Burgard M, Melard A, Girard P-M, et al. A low HIV-DNA level in peripheral blood mononuclear cells at antiretroviral treatment interruption predicts a higher probability of maintaining viral control. Aids. 2015;29:2003-7. https://doi.org/10.1097/ QAD.00000000000000734.

53. Williams JP, Hurst J, Stöhr W, Robinson N, Brown H, Fisher M, et al. HIV-1 DNA predicts disease progression and post-treatment virological control. Elife. 2014;3:e03821.

54. Pinzone MR, Graf E, Lynch L, McLaughlin B, Hecht FM, Connors M, et al. Monitoring integration over time supports a role for $C T L$ and ongoing replication as determinants of reservoir size. J Virol. 2016. https://doi. org/10.1128/JVI.00242-16.

55. Koelsch KK, Boesecke C, McBride K, Gelgor L, Fahey P, Natarajan V, et al. Impact of treatment with raltegravir during primary or chronic HIV infection on RNA decay characteristics and the HIV viral reservoir. Aids. 2011;25:2069-78. https://doi.org/10.1097/QAD.0b013e32834b9658.

56. Murray JM, McBride K, Boesecke C, Bailey M, Amin J, Suzuki K, et al. Integrated HIV DNA accumulates prior to treatment while episomal HIV DNA records ongoing transmission afterwards. Aids. 2012;26:543-50.

57. Buzon MJ, Martin-Gayo E, Pereyra F, Ouyang Z, Sun H, Li JZ, et al. Longterm antiretroviral treatment initiated at primary HIV-1 infection affects the size, composition, and decay kinetics of the reservoir of HIV-1-infected CD4 T cells. J Virol. 2014;88:10056-65. https://doi.org/10.1128/ JVI.01046-14.

58. Murray JM, Zaunders JJ, McBride KL, Xu Y, Bailey M, Suzuki K, et al. HIV DNA subspecies persist in both activated and resting memory CD4 + T cells during antiretroviral therapy. J Virol. 2014;88:3516-26. https://doi. org/10.1128/JVI.03331-13.

59. Radebe M, Gounder K, Mokgoro M, Ndhlovu ZM, Mncube Z, Mkhize $L$, et al. Broad and persistent gag-specific CD8 + T-cell responses are associated with viral control but rarely drive viral escape during primary HIV-1 infection. Aids. 2015;29:23-33. https://doi.org/10.1097/ QAD.0000000000000508.

60. Deng K, Pertea M, Rongvaux A, Wang L, Durand CM, Ghiaur G, et al. Broad CTL response is required to clear latent HIV-1 due to dominance of escape mutations. Nature. 2015;517:381-5. https://doi.org/10.1038/ nature 14053.

61. Streeck H, Jolin JS, Qi Y, Yassine-Diab B, Johnson RC, Kwon DS, et al. Human immunodeficiency virus type 1-specific CD8 + T-cell responses during primary infection are major determinants of the viral set point and loss of CD4 + T cells. J Virol. 2009;83:7641-8. https://doi. org/10.1128/JVI.00182-09.
62. Trautmann L, Mbitikon-Kobo F-M, Goulet J-P, Peretz Y, Shi Y, Van Grevenynghe J, et al. Profound metabolic, functional, and cytolytic differences characterize HIV-specific CD8 T cells in primary and chronic HIV infection. Blood. 2012;120:3466-77. https://doi.org/10.1182/ blood-2012-04-422550

63. Descours B, Avettand-Fenoel V, Blanc C, Samri A, Mélard A, Supervie V, et al. Immune responses driven by protective human leukocyte antigen alleles from long-term nonprogressors are associated with low HIV reservoir in central memory CD4 T cells. Clin Infect Dis. 2012;54:1495-503.

64. Bruner KM, Murray AJ, Pollack RA, Soliman MG, Laskey SB, Capoferri AA, et al. Defective proviruses rapidly accumulate during acute HIV-1 infection. Nat Med. 2016;22:1043-9. https://doi.org/10.1038/nm.4156.

65. Estes JD, Kityo C, Ssali F, Swainson L, Nganou Makamdop K, Del Prete GQ, et al. Defining total-body AIDS-virus burden with implications for curative strategies. Nat Publ Gr. 2017. https://doi.org/10.1038/nm.4411.

66. Graf EH, Mexas AM, Yu JJ, Shaheen F, Liszewski MK, Di Mascio M, et al. Elite suppressors harbor low levels of integrated HIV DNA and high levels of 2-LTR circular HIV DNA compared to HIV + patients on and off HAART. PLoS Pathog. 2011;7:e1001300.

67. Mens H, Kearney M, Wiegand A, Shao W, Schønning K, Gerstoft J, et al. HIV-1 continues to replicate and evolve in patients with natural control of HIV infection. J Virol. 2010;84:12971-81. https://doi.org/10.1128/ JVI.00387-10.

68. Julg B, Pereyra F, Buzón MJ, Piechocka-Trocha A, Clark MJ, Baker BM, et al. Infrequent recovery of HIV from but robust exogenous infection of activated CD4 + T cells in HIV elite controllers. Clin Infect Dis. 2010:51:233-8.

69. O'Connell KA, Brennan TP, Bailey JR, Ray SC, Siliciano RF, Blankson $J \mathrm{~N}$. Control of HIV-1 in elite suppressors despite ongoing replication and evolution in plasma virus. JVirol. 2010;84:7018-28. https://doi. org/10.1128/JVI.00548-10.

70. Connick E, Mattila T, Folkvord JM, Schlichtemeier R, Meditz AL, Ray MG, et al. CTL fail to accumulate at sites of HIV-1 replication in lymphoid tissue. J Immunol. 2007;178:6975-83. https://doi.org/10.4049/ jimmunol.178.11.6975.

71. Fukazawa Y, Lum R, Okoye AA, Park H, Matsuda K, Bae JY, et al. B cell follicle sanctuary permits persistent productive simian immunodeficiency virus infection in elite controllers. Nat Med. 2015;21:132-9. https://doi. org/10.1038/nm.3781.

72. Connick E, Folkvord JM, Lind KT, Rakasz EG, Miles B, Wilson NA, et al. Compartmentalization of simian immunodeficiency virus replication within secondary lymphoid tissues of rhesus macaques is linked to disease stage and inversely related to localization of virusspecific CTL. J Immunol. 2014;193:5613-25. https://doi.org/10.4049/ jimmunol.1401161.

73. Yerly S, Gunthard HF, Fagard C, Joos B, Perneger TV, Hirschel B, Perrin L. Proviral HIV-DNA predicts viral rebound and viral setpoint after structured treatment interruptions. Res Lett. 2004;18:1951-64.

74. Piketty C, Weis L, Assoumou L, Burgard M, Mélard A, Ragnaud JM, et al. ANRS 116 Salto Study Group. A high HIV DNA level in PBMCs at antiretroviral treatment interruption predicts a shorter time to treatment resumption, independently of the CD4 nadir. J Med Virol. 2010:82:1819-28.

75. Hurst J, Hoffmann M, Pace M, Williams JP, Thornhill J, Hamlyn E, et al. Immunological biomarkers predict HIV-1 viral rebound after treatment interruption. Nat Commun. 2015;6:8495. https://doi.org/10.1038/ ncomms9495.

76. Graf EH, Pace MJ, Peterson BA, Lynch LJ, Chukwulebe SB, Mexas AM, et al. Gag-positive reservoir cells are susceptible to HIV-specific cytotoxic T lymphocyte mediated clearance in vitro and can be detected in vivo [corrected]. PLoS ONE. 2013;8:e71879. https://doi.org/10.1371/ journal.pone.0071879.

77. Chan CN, Trinité B, Lee CS, Mahajan S, Anand A, Wodarz D, et al. HIV-1 latency and virus production from unintegrated genomes following direct infection of resting CD4 T cells. Retrovirology. 2016;13:1. https:// doi.org/10.1186/s12977-015-0234-9.

78. Elliott JH, Wightman F, Solomon A, Ghneim K, Ahlers J, Cameron MJ, et al. Activation of HIV transcription with short-course vorinostat in HIVinfected patients on suppressive antiretroviral therapy. PLoS Pathog. 2014:10:1-19. 
79. Rasmussen TA, Tolstrup M, Brinkmann CR, Olesen R, Erikstrup C, Solomon A, Winckelmann A, Palmer S, Dinarello C, Buzon M, Lichterfeld M, Lewin SR, Østergaard LSO. Panobinostat, a histone deacetylase inhibitor, for latent-virus reactivation in HIV-infected patients on suppressive antiretroviral therapy: a phase 1/2, single group, clinical trial. Lancet HIV. 2014; $1: \mathrm{e} 13-21$.

80. Leth S, Schleimann MH, Nissen SK, Højen JF, Olesen R, Graversen ME, Jørgensen S, Kjær AS, Denton PW, Mørk A, Sommerfelt MA, Krogsgaard $\mathrm{K}$, Østergaard L, Rasmussen TA, Tolstrup MSO. Combined effect of Vacc$4 \mathrm{x}$, recombinant human granulocyte macrophage colony-stimulating factor vaccination, and romidepsin on the HIV-1 reservoir (REDUC): a single-arm, phase 1B/2A trial. Lancet HIV. 2016;3:e463-72.

81. Mexas AM, GrafEH, Pace MJ, Yu JJ, Papasavvas E, Azzoni L, et al. Concurrent measures of total and integrated HIV DNA monitor reservoirs and ongoing replication in eradication trials. AIDS. 2012;26:2295-306. https://doi.org/10.1097/QAD.0b013e32835a5c2f.

82. Cardozo EF, Andrade A, Mellors JW, Kuritzkes DR, Perelson AS, Ribeiro RM. Treatment with integrase inhibitor suggests a new interpretation of HIV RNA decay curves that reveals a subset of cells with slow integration. PLoS Pathog. 2017;13:1-18.

83. Pace MJ, Graf EH, O'Doherty U. HIV 2-long terminal repeat circular DNA is stable in primary CD4 + T cells. Virology. 2013;441:18-21.

84. Andrade A, Guedj J, Rosenkranz SL, Lu D, Mellors J, Kuritzkes DR, et al. Early HIV RNA decay during raltegravir-containing regimens exhibits two distinct subphases (1a and 1b). AIDS. 2015;29:2419-26. https://doi. org/10.1097/QAD.0000000000000843.

85. Liszewski MK, Yu JJ, O'Doherty U. Detecting HIV-1 integration by repetitive-sampling Alu-gag PCR. Methods. 2009;47:254-60. https://doi. org/10.1016/j.ymeth.2009.01.002.

86. Yu JJ, Wu TL, Liszewski MK, Dai J, Swiggard WJ, Baytop C, et al. A more precise HIV integration assay designed to detect small differences finds lower levels of integrated DNA in HAART treated patients. Virology. 2008;379:78-86. https://doi.org/10.1016/j.virol.2008.05.030.

87. Lada, Steven M et al. Novel Assay to Measure Integrated HIV DNA in PBMC from ART-Suppressed Persons. CROI. 2017; Poster 300.

88. Kumar R, Vandegraaff N, Mundy L, Burrell CJ, Li P. Evaluation of PCRbased methods for the quantitation of integrated HIV-1 DNA. J Virol Methods. 2002;105:233-46.

89. Vandergeeten C, Fromentin R, Merlini E, Lawani MB, DaFonseca S, Bakeman W, et al. Cross-clade ultrasensitive PCR-based assays to measure HIV persistence in large-cohort studies. J Virol. 2014;88:12385-96. https://doi.org/10.1128/JVI.00609-14.
90. Symons J, Chopra A, Malatinkova E, Spiegelaere W De, Leary S, Cooper $D$, et al. HIV integration sites in latently infected cell lines: evidence of ongoing replication. Retrovirology. 2017;14:2.

91. De Spiegelaere W, Malatinkova E, Lynch L, Van Nieuwerburgh F, Messiaen P, O'Doherty U, et al. Quantification of integrated HIV DNA by repetitive-sampling Alu-HIV PCR on the basis of poisson statistics. Clin Chem. 2014;60:886-95. https://doi.org/10.1373/clinchem.2013.219378.

92. Rouzioux C, Avettand-Fenoel V. Total HIV-DNA: a global marker of HIV persistence. Retrovirology. 2018;15(1). (In press).

93. Besson GJ, Lalama CM, Bosch RJ, Gandhi RT, Bedison MA, Aga E, et al. HIV-1 DNA decay dynamics in blood during more than a decade of suppressive antiretroviral therapy. Clin Infect Dis. 2014;59:1312-21. https://doi.org/10.1093/cid/ciu585.

94. Mendoza D, Johnson SA, Peterson BA, Natarajan V, Salgado M, Robin L, et al. Comprehensive analysis of unique cases with extraordinary control over HIV replication comprehensive analysis of unique cases with extraordinary control over HIV replication. Blood. 2014;119:4645-55.

95. Kiselinova M, De Spiegelaere W, Buzon MJ, Malatinkova E, Lichterfeld M, Vandekerckhove L. Integrated and total HIV-1 DNA predict ex vivo viral outgrowth. PLoS Pathog. 2016;12:e1005472.

96. Bruner KM, Hosmane NN, Siliciano RF. Towards an HIV-1 cure: measuring the latent reservoir Katherine. Trends Microbiol. 2015;23:192-203.

97. Imamichi H, Dewar RL, Adelsberger JW, Rehm CA, O'Doherty U, Paxinos EE, et al. Defective HIV-1 proviruses produce novel protein-coding RNA species in HIV-infected patients on combination antiretroviral therapy. Proc Natl Acad Sci USA. 2016;113:201609057. https://doi.org/10.1073/ pnas.1609057113.

98. Lewinski MK, Bisgrove D, Shinn P, Chen H, Hoffmann C, Hannenhalli $\mathrm{S}$, et al. Genome-wide analysis of chromosomal features repressing human immunodeficiency virus transcription. J Virol. 2005;79:6610-9. https://doi.org/10.1128/JVI.79.11.6610-6619.2005.

99. Han Y, Lassen K, Monie D, Sedaghat AR, Shimoji S, Liu X, et al. Resting CD4 + T cells from human immunodeficiency virus type 1 (HIV-1)-infected individuals carry integrated HIV-1 genomes within actively transcribed host genes. JVirol. 2004;78:6122-33. https://doi.org/10.1128/ JVI.78.12.6122-6133.2004.

100. Hughes $\mathrm{S}$, Coffin J. What integration sites tell us about HIV persistence. Cell Host Microbe. 2016;19:588-98.

101. Maldarelli F, Wu X, Su L, Simonetti FR, Shao W, Hill S, et al. Specific HIV integration sites are linked to clonal expansion and persistence of infected cells. Science. 2014;345:2-7. https://doi.org/10.1126/ science.1254194.

\section{Submit your next manuscript to BioMed Central and we will help you at every step:}

- We accept pre-submission inquiries

- Our selector tool helps you to find the most relevant journal

- We provide round the clock customer support

- Convenient online submission

- Thorough peer review

- Inclusion in PubMed and all major indexing services

- Maximum visibility for your research

Submit your manuscript at www.biomedcentral.com/submit 